\title{
Autosomal Recessive Cerebellar Ataxias With Elevated Alpha-Fetoprotein: Uncommon Diseases, Common Biomarker
}

\author{
Mathilde Renaud, MD, PhD, ${ }^{1,2}$ Christine Tranchant, MD, $\mathrm{PhD}, 3,4,5$ Michel Koenig, MD, $\mathrm{PhD},{ }^{6}$ and \\ Mathieu Anheim, MD, PhD $3,4,5^{\star}$ \\ 'Service de Génétique Clinique, CHRU de Nancy, Nancy, France \\ ${ }^{2}$ INSERM-U1256 NGERE, Université de Lorraine, Nancy, France \\ ${ }^{3}$ Service de Neurologie, Hôpitaux Universitaires de Strasbourg, Strasbourg, France \\ ${ }^{4}$ Institut de Génétique et de Biologie Moléculaire et Cellulaire (IGBMC), INSERM-U964/CNRS-UMR7104/Université de \\ Strasbourg, IIIkirch, France \\ ${ }^{5}$ Fédération de Médecine Translationnelle de Strasbourg (FMTS), Université de Strasbourg, Strasbourg, France \\ ${ }^{6}$ Laboratoire de Génétique de Maladies Rares EA7402, Institut Universitaire de Recherche Clinique, Université de Montpellier, \\ CHU Montpellier, Montpellier, France
}

\begin{abstract}
Fetoprotein (AFP) is a biomarker of several autosomal recessive cerebellar ataxias (ARCAs), especially ataxia telangiectasia (AT) and ataxia with oculomotor apraxia (AOA) type 2 (AOA2). More recently, slightly elevated AFP has been reported in $A O A 1$ and AOA4. Interestingly, AOA1, AOA2, AOA4, and AT are overlapping ARCAs characterized by oculomotor apraxia, with oculocephalic dissociation, choreo-dystonia, and/or axonal sensorimotor neuropathy, in addition to cerebellar ataxia with cerebellar atrophy. The genetic backgrounds in these disorders play central roles in nuclear maintenance through DNA repair [ATM (AT), APTX (AOA1), or PNKP (AOA4)] or RNA termination [SETX (AOA2)]. Partially discriminating thresholds of AFP have been
\end{abstract}

Autosomal recessive cerebellar ataxias (ARCAs) are a heterogeneous group of inherited neurodegenerative disorders that affect the cerebellum. Cerebellar ataxia (CA) with onset before age 30 years in a context of consanguinity and/or similar cases in siblings with healthy parents is

${ }^{*}$ Correspondence to: Prof. Mathieu Anheim, Département de Neurologie, Hôpitaux Universitaires de Strasbourg, Hôpital de Hautepierre 1, Avenue Molière, 67098 Strasbourg Cedex, France;

E-mail: mathieu.anheim@chru-strasbourg.fr proposed as a way to distinguish between ARCAs with elevated AFP. In these entities, elevated AFP may be an epiphenomenon as a result of liver transcriptional dysregulation. AFP is a simple and reliable biomarker for the diagnosis of ARCA in performance and interpretation of next-generation sequencing. Here, we evaluated clinical, laboratory, imaging, and molecular data of the group of ARCAs that share elevated AFP serum levels that have been described in the past two decades. (C) 2020 International Parkinson and Movement Disorder Society

Key Words: recessive ataxia; alpha-fetoprotein; oculomotor apraxia; DNA/RNA repair suggestive of ARCA. Some biomarkers, such as alphafetoprotein (AFP), are crucial for the diagnosis of ARCAs. ${ }^{1}$

Recently, a group of ARCAs caused by mutations in genes implicated in DNA repair and/or transcriptional deficiencies has emerged. They are characterized by the combination of CA with oculomotor disturbances, such as oculomotor apraxia (OMA; see Supporting Information Video S1 and Fig. 1) $)^{2,3}$ or oculocephalic dissociation (OCD; see Supporting Information Video S6 and Fig. 1), with dystonia, chorea, sensorimotor axonal neuropathy, and elevated AFP serum level. ${ }^{1}$ OMA is identified by constant horizontal saccades with increased latency sometimes associated with hypometric staircase saccades during head thrust and/or OCD that may also provide clues. OMA also includes difficulty in making voluntary saccades and may be responsible for OCD in some patients. OMA is easier to diagnose with 

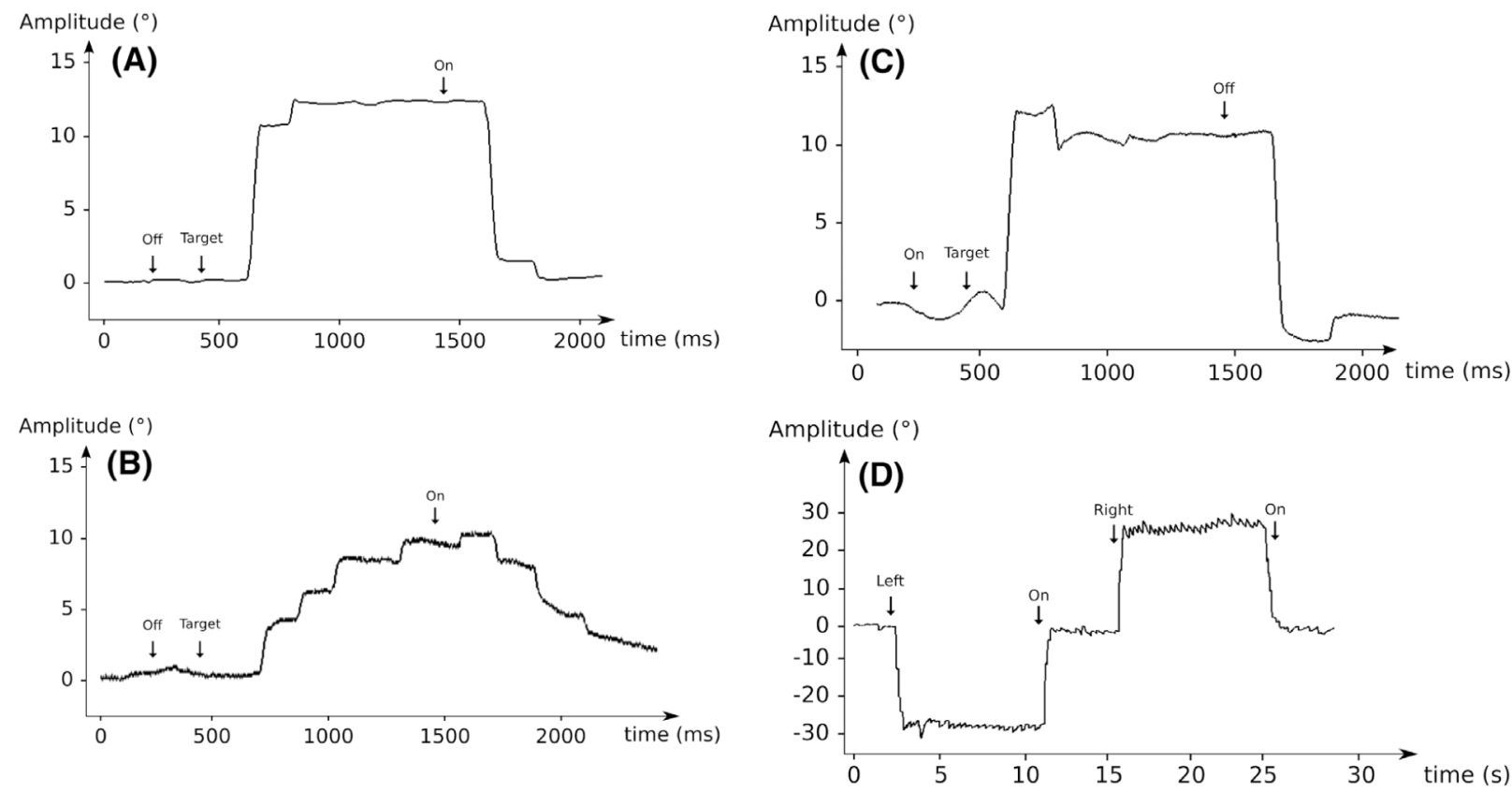

FIG. 1. Eye movement recordings. (A) Normal rightward saccade of control subject with a normal latency. (B) Hypometric rightward saccade with markedly increased latency in a patient with ataxia with oculomotor apraxia type 1 (AOA1). The latency increases in the patient with a saccade, starting later than the control. (C) Hypermetric centrifugal rightward saccade and hypermetric centripetal saccade in a patient with ataxia telangiectasia. (D) Gazeevoked nystagmus in a patient with AOA2. Left, target on the left; off, center off; on, center on; right, target on the right; target, right target appears.

oculographic recording and may not be present in some patients with ataxia with oculomotor apraxia type 1 (AOA1) or AOA2, which can be a misleading factor. OCD dissociation is a delay of eye movement during a task of head rotation where the head reaches the target before the eyes. OCD may be caused by oculomotor apraxia or more frequently by very hypometric horizontal saccades. OCD is easier to diagnose clinically than OMA.

This new group includes ataxia telangiectasia [AT, ataxia telangiectasia mutated $(A T M)],{ }^{4}$ ataxia with AOA1 (APTX), ${ }^{5}$ AOA2 [SETX (senataxin) $],{ }^{6}$ and

TABLE 1. The ARCAs with elevated AFP

\begin{tabular}{lllc}
\hline Mechanism & Gene & Protein & Disease \\
\hline $\begin{array}{l}\text { DNA double-strand break } \\
\text { repair }\end{array}$ & ATM & ATM & AT \\
$\begin{array}{l}\text { DNA single-strand break } \\
\text { repair }\end{array}$ & APTX & Aprataxin & A0A1/EOAH \\
RNA termination/maturation & PNKP & PNKP & A0A4 \\
(MCSZ) & AOA2 \\
Channel & ANO10 & AN0nataxin & ANS4) \\
& & TMEM16K & ARCA3 \\
\hline
\end{tabular}

Abbreviations: ARCA, autosomal recessive ataxia; AFP, alpha-fetoprotein; ATM, ataxia telangiectasia mutated; AT, ataxia telangiectasia; AOA1, ataxia with oculomotor apraxia type 1; $\mathrm{EOAH}$, early-onset ataxia with oculomotor apraxia and hypoalbuminemia; PNKP, polynucleotide kinase $3^{\prime}$-phosphatase; AOA4, ataxia with oculomotor apraxia type 4; MCSZ, microcephaly, seizures, and developmental delay; AOA2, ataxia with oculomotor apraxia type 2 (AOA2); ALS4, amyotrophic lateral sclerosis 4 (juvenile); TMEM16K, transmembrane protein 16K; ARCA3, autosomal recessive ataxia type 3 (ARCA3).
AOA4 [polynucleotide kinase $3^{\prime}$-phosphatase (PNKP)]. ${ }^{7}$ Here we review the group of ARCAs associated with an elevated AFP serum level (AT, AOA1, AOA2, and AOA4) (Table 1), which are rare, similar diseases that must be recognized and distinguished from each other for the best care of these patients.

\section{AT, ATM Gene (OMIM: 208900)}

AT is the second most frequent ARCA after Friedreich's disease. It is characterized by neurodegeneration, immunodeficiency, and predisposition to malignancy; with progressive CA, OCD and/or OMA, dystonia, sensorimotor axonal neuropathy, and elevated AFP serum level. ${ }^{4,8,9}$ Disease onset occurs most frequently around age 2 years and worsens progressively, leading to the loss of locomotion by 10 years, followed by death within the next decade. ${ }^{10}$ Dystonia is frequently accompanied by chorea, myoclonus, tremor, or parkinsonism. ${ }^{11,12}$ According to Levy and Lang, ${ }^{12}$ the prevalence of movement disorders during the course of AT includes cerebellar symptoms (96\%), myoclonus $(92 \%)$, dystonia $(89 \%)$, choreoathetosis $(89 \%)$, tremor $(74 \%)$, and parkinsonism $(41 \%)$. Brain magnetic resonance imaging (MRI) reveals cerebellar atrophy. With later onset, a milder phenotype and consequently a longer life span are possible. Patients with the milder expression of AT typically have neurological deficits in childhood with slower age-related neurodegeneration. The predominant neurological symptoms at disease 
TABLE 2. Clinical and biological characteristics of ARCAs with elevated AFP

\begin{tabular}{|c|c|c|c|c|c|c|}
\hline & AT & ATLD & AOA1/EOAH & $\mathrm{AOA} 2$ & AOA4 & ARCA3 \\
\hline $\begin{array}{l}\text { Age of onset } \\
\text { (years) }\end{array}$ & $\begin{array}{l}\text { Infancy/2-5 (possible late } \\
\text { onset) }\end{array}$ & Childhood & Infancy/childhood 2-10 & Teens 10-15 & $\begin{array}{l}\text { Infancy/childhood } \\
1-9\end{array}$ & $\begin{array}{l}\text { Adulthood/ } \\
10-40\end{array}$ \\
\hline $\begin{array}{l}\text { Age of onset, } \\
\text { extreme range } \\
\text { (years) }\end{array}$ & $1-41$ & $3-47$ & $2-49$ & $7-30$ & $1-10$ & $6-43$ \\
\hline $\begin{array}{l}\text { Progression/ } \\
\text { Severity }\end{array}$ & Rapid/Severe & $\begin{array}{l}\text { Intermediate/ } \\
\text { Moderate }\end{array}$ & Rapid/Moderate & $\begin{array}{l}\text { Rapid/ } \\
\text { Moderate }\end{array}$ & Rapid/Moderate & $\begin{array}{l}\text { Slow/ } \\
\quad \text { Moderate }\end{array}$ \\
\hline $\begin{array}{l}\text { Neurological } \\
\text { signs }\end{array}$ & $\begin{array}{l}\text { Dystonia } \\
\text { Chorea } \\
\text { Neuropathy } \\
\text { OCD/OMA }\end{array}$ & $\begin{array}{l}\text { Dystonia } \\
\text { Chorea } \\
\text { Neuropathy } \\
\text { OMA }\end{array}$ & $\begin{array}{l}\text { Intellectual disability } \\
\text { Dystonia } \\
\text { Chorea Neuropathy } \\
\text { OCD } \\
\text { Hypometric saccades } \\
\text { Optional OMA }\end{array}$ & $\begin{array}{l}\text { Dystonia } \\
\text { Chorea } \\
\text { Neuropathy } \\
\text { Optional OCD } \\
\text { Optional OMA }\end{array}$ & $\begin{array}{l}\text { Dystonia } \\
\text { Cognitive } \\
\text { impairment } \\
\text { Neuropathy } \\
\text { OMA }\end{array}$ & $\begin{array}{l}\text { Extensor } \\
\text { plantar } \\
\text { reflexes } \\
\text { Spasticity } \\
\text { Cognitive } \\
\text { decline } \\
\text { Downbeat } \\
\text { nystagmus } \\
\text { Lack of } \\
\text { neuropathy }\end{array}$ \\
\hline $\begin{array}{l}\text { Extraneurological } \\
\text { signs }\end{array}$ & $\begin{array}{l}\text { Telangiectasias } \\
\text { Immunodeficiency and } \\
\quad \text { recurrent infections } \\
\text { Photosensitivity } \\
\text { Risk for cancers (lymphoid } \\
\quad \text { malignancies) }\end{array}$ & $\begin{array}{l}\text { Lack of } \\
\text { telangiectasias } \\
\text { Possible risk for } \\
\text { cancers }\end{array}$ & None & None & None & None \\
\hline $\begin{array}{l}\text { AFP elevation } \\
\text { (levels) }\end{array}$ & $\begin{array}{l}\text { Marked: mostly } 200 \mu \mathrm{g} / \mathrm{L} \\
\text { increase with disease } \\
\text { duration }\end{array}$ & $\begin{array}{l}\text { Normal level: } \\
\quad<5 \mu \mathrm{g} / \mathrm{L}\end{array}$ & $\begin{array}{l}\text { Slightly increased in } 40 \% \\
\text { of A0A1: } 5-20 \mu \mathrm{g} / \mathrm{L} \\
\text { increase with disease } \\
\text { duration }\end{array}$ & $\begin{array}{l}\text { Always } \\
\text { increased: } \\
15-65 \mu \mathrm{g} / \mathrm{L} \\
\text { stable }\end{array}$ & $\begin{array}{l}\text { Variably increased: } \\
\quad 10-30 \mu \mathrm{g} / \mathrm{L}\end{array}$ & $\begin{array}{l}\text { Rarely } \\
\text { increased } \\
5-15 \mu \mathrm{g} / \mathrm{L}\end{array}$ \\
\hline $\begin{array}{l}\text { AFP, extreme } \\
\text { range }(\mu \mathrm{g} / \mathrm{L})\end{array}$ & $5-2800$ & $0-7$ & $1-17$ & $5-185$ & $6-30$ & $1-17$ \\
\hline $\begin{array}{l}\text { Others } \\
\text { biomarkers }\end{array}$ & $\begin{array}{l}\text { Mixed immune deficiency } \\
\text { (CD4/CD8 deficiency, } \\
\text { IgA/lgG deficiency) } \\
\text { Chromosomal } \\
\text { rearrangements ( } 7: 14 \\
\text { translocations) on the } \\
\text { karyotype }\end{array}$ & & $\begin{array}{l}\text { Optional hypoalbuminemia } \\
\text { and } \\
\text { hypercholesterolemia }\end{array}$ & Elevated CK & $\begin{array}{l}\text { Elevated CK } \\
\text { Optional } \\
\quad \text { hypoalbuminemia }\end{array}$ & \\
\hline
\end{tabular}

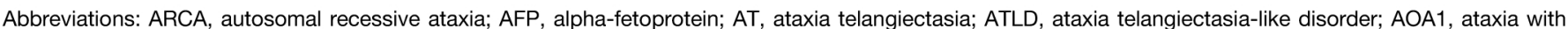

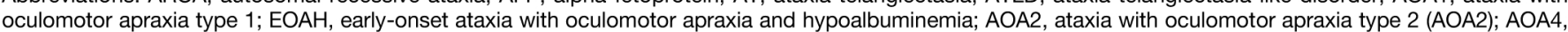

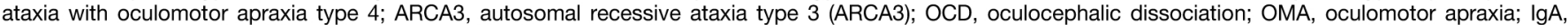
immunoglobulin A; lgG, immunoglobulin G; CK, creatine kinase.

onset and during the early stages may be dystonia, myoclonus, or tremor, with ataxia appearing subsequently. AFP should therefore be considered part of the workup in early-onset, unexplained dystonia. OMA may also appear later or not at all $^{9}$ (Tables 2 and 3; Supporting Inofrmation Videos S1, S2, and S3).

Extraneurological findings are conjunctival, auricular, or buccal telangiectasia; immunodeficiency with recurrent infections (sinusitis and lung infections caused by Hemophilus influenzae or Streptococcus pneumoniae), increased cancer risk (especially hematological, such as lymphomas and leukemias, but also solid tumors $)^{9,13}$; and sensitivity to ionizing radiation. Follow-up of patients with AT is recommended to prevent or treat infections (intravenous immunoglobulin, antibiotics) or malignancies. Early detection may allow a better prospective evaluation of AT and thus assist in more effective treatment for both the neurological and immune abnormalities. ${ }^{14,15}$ Van Os et al. ${ }^{16}$ have proposed guidelines for response to the medical problems encountered during the course of AT with regard to neurological, immunological, infectious, oncological, endocrinological, and nutritional disorders, as well as perioperative risk. In this particular form of AT, immunodeficiency may occur but is less common, whereas malignancies tend to appear later in life and include a higher proportion of nonhematopoietic cancers. ${ }^{9}$

The AFP serum level is markedly increased in $90 \%$ of patients, often greater than $100 \mu \mathrm{g} / \mathrm{L}$ (normal $<5 \mu \mathrm{g} / \mathrm{L}$ ). A few patients with AT did not experience AFP elevation or a delayed increase of AFP during the clinical course of the disease. ${ }^{17}$ CD4 and CD8 immunodeficiencies, IgA or IgG immunodeficiency, and chromosomal translocations (especially $7: 14$ on the 
TABLE 3. Comparison of the clinical features in ARCAs with OCD/OMA

\begin{tabular}{|c|c|c|c|c|c|}
\hline Neurological features & AT & ATLD & AOA1 & $\mathrm{AOA} 2$ & AOA4 \\
\hline Intellectual disability & $\begin{array}{l}+/- \\
\text { Learning difficulties }\end{array}$ & - & ++ & - & ++ \\
\hline Cerebellar atrophy & ++ & ++ & ++ & ++ & ++ \\
\hline Sensorimotor polyneuropathy & ++ & + & +++ & ++ & ++ \\
\hline Dystonia & $\begin{array}{l}+++ \\
\text { May be the predominant sign }\end{array}$ & ++ & ++ & ++ & ++ \\
\hline Chorea & ++ & + & $\begin{array}{l}++ \\
\text { Could improve with disease progression }\end{array}$ & + & $?$ \\
\hline Myoclonus & ++ & $?$ & + & + & $?$ \\
\hline OCD & ++ & + & ++ & + & ++ \\
\hline OMA & Genuine OMA & & Pseudo-OMA (hypometric saccades) > OMA & Not severe & Early and severe \\
\hline
\end{tabular}

Abbreviations: ARCA, autosomal recessive ataxia; OCD, oculocephalic dissociation; OMA, oculomotor apraxia; AT, ataxia telangiectasia; ATLD, ataxia telangiectasia-like disorder; AOA1, ataxia with oculomotor apraxia type 1; AOA2, ataxia with oculomotor apraxia type 2; AOA4, ataxia with oculomotor apraxia type 4.

karyotype $^{8}$ ) are frequent. ${ }^{18}$ The variability of AT phenotypes and the large size of ATM (66 exons) may render diagnosis difficult; in support, laboratory testing proves very helpful.

The ATM gene ${ }^{19}$ encodes a phosphatidylinositol 3-kinase involved in cell-cycle progression, cellular response to DNA alterations, and maintenance of genome stability ${ }^{4}$ (Table 1 ).

Two rare forms of ataxia telangiectasia-like disorder (ATLD) have been described with a similar clinical picture and the same pathway, yet without AFP elevation: ATLD [meiotic recombination 11 (MRE11) gene] and ATLD2 [proliferating cell nuclear antigen (PCNA) gene]. ${ }^{20-22}$ The MRE11 gene encodes a protein (Mre11) with nuclease and DNA-binding activity. Together with Rad50 (DNA-repair protein 50) and Nbs1 (Nijmegen breakage syndrome protein 1 or Nibrin), Mre11 forms the MRN complex, which is a target of ATM kinase and is also involved in the signaling network of cellular response to DNA damage (Fig. 2B).

\section{AOA1, APTX Gene (OMIM: 208920)}

AOA1 has been described as a CA of early onset, most frequently before age 10 years. ${ }^{23}$ Patients suffer from intellectual deficiency $(50 \%)$ accompanied by cerebellar atrophy, OCD and/or OMA, choreo-dystonia, and severe peripheral neuropathy.,24 OCD and/or OMA may not be present at disease onset but are expressed a few years later (Tables 2 and 3; Supporting Information Videos S6, S7, and S8).

Recently, we reported that OMA correlates with diseases of greater severity; the p.Trp279* APTX mutation was the most frequent among the white population, whereas the APTX missense mutations were associated with a milder phenotype. ${ }^{25}$ In Japan, AOA1 is the most frequent ARCA, named early-onset AOA and hypoalbuminemia.

During the course of AOA1, decreased serum albumin levels and elevated total cholesterol levels may be observed, suggesting hypoalbuminemia and hypercholesterolemia, found in $63 \%$ of patients, as the most characteristic biochemical findings in AOA1, even if they are optional. ${ }^{25,48}$ AFP serum level was reported to be elevated in $40 \%$ of the 80 patients with AOA 1 studied. $^{25,26}$ This slight increase of AFP, ranging from 15 to $20 \mu \mathrm{g} / \mathrm{L}$, may be significant.

Whether patients with AOA1 have coenzyme Q10 (CoQ10) deficiency is not yet clear. ${ }^{26,27}$

\section{AOA2, SETX Gene (OMIM: 606002)}

Disease onset in AOA2 is usually between ages 12 and 20 years, which is later than in AOA1 and AT. ${ }^{8,24,28}$ Patients with AOA2 experience progressive CA, along with sensorimotor neuropathy, occasional OCD and/or OMA, strabismus, chorea, dystonia, and elevated serum AFP levels. Brain MRI reveals marked cerebellar atrophy (Tables 2 and 3; Supporting Information Videos S9, S10, S11, and S12). Recently, three cases of disruption of spermatogenesis and infertility were reported in AOA2. ${ }^{29}$

AFP serum levels are between 15 and $65 \mu \mathrm{g} / \mathrm{L}$, averaging around $50 \mu \mathrm{g} / \mathrm{L} .{ }^{30}$ Healthy subjects who carry a heterozygous SETX mutation may have a mildly elevated AFP serum level, while laboratory examination may reveal elevated creatine kinase serum levels ${ }^{31,32}$ (Table 2).

SETX encodes senataxin, a protein containing a DNA/RNA helicase domain, which is involved in RNA processing, RNA termination, and coordination of transcription events, and may also act as a genome guardian $^{6,28,32}$ (Table 1 and Fig. 3). Missense mutations 
(A) DNA single-strand break repair (SSBR)

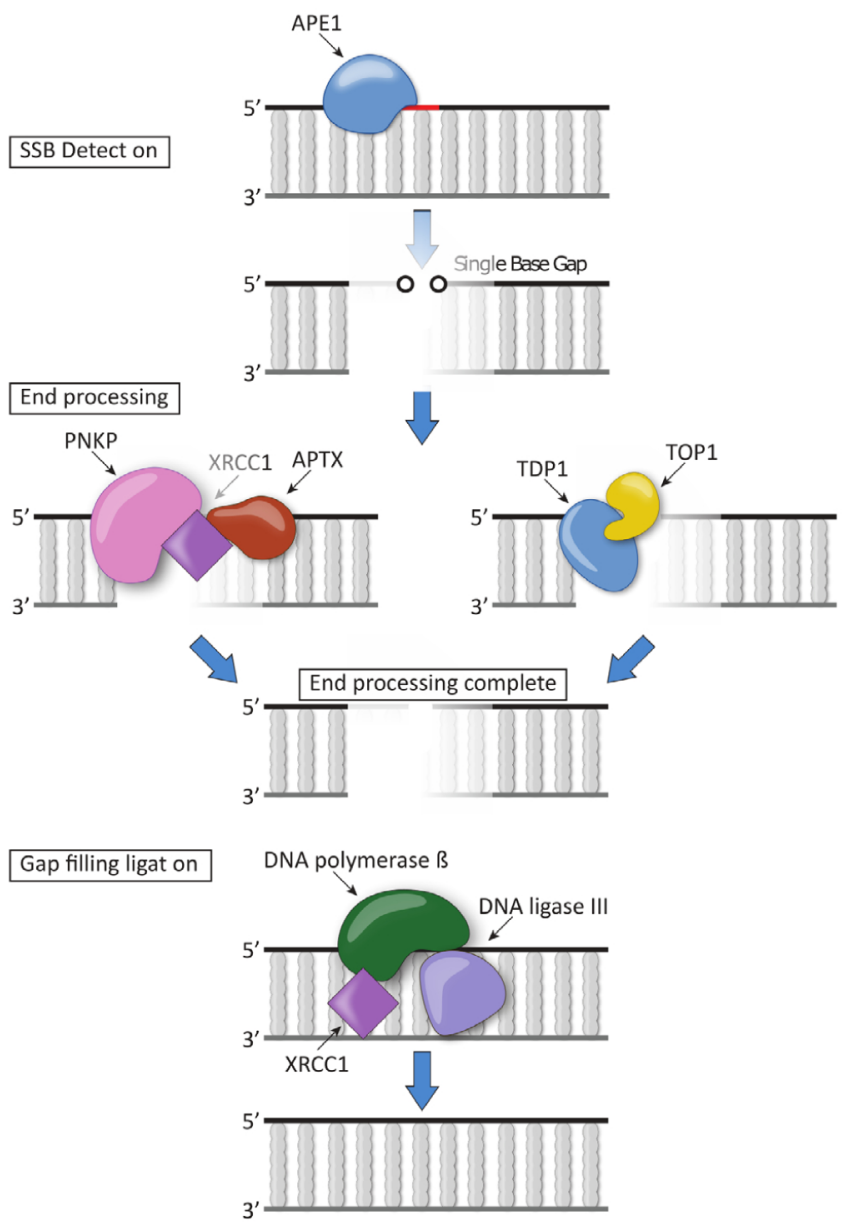

(B) DNA double-strand break repair (DSBR)
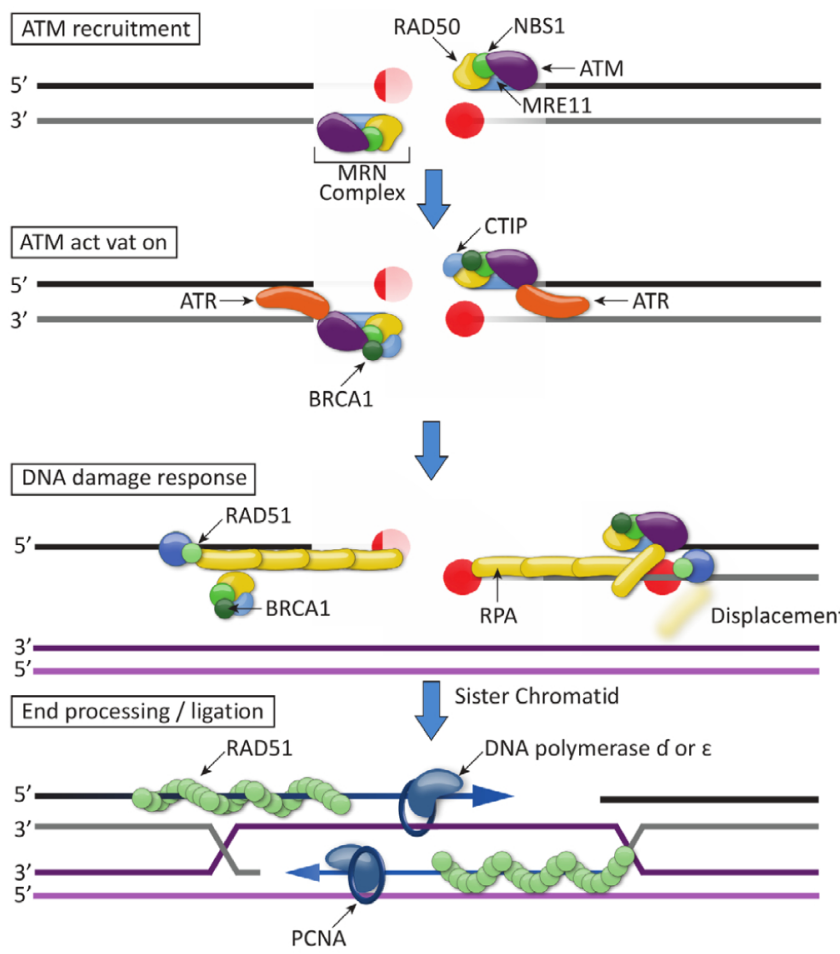

FIG. 2. DNA repair in autosomal recessive cerebellar ataxias (ARCAs). Two distinct groups of ARCAs are caused by defective DNA repair. (A) DNA single-strand break repair (SSBR). The first group includes ataxia with oculomotor apraxia type 1 (AOA1) caused by mutations in APTX AOA4 (PNKP), spinocerebellar ataxia with axonal neuropathy (SCAN1, TDP1), and cerebellar ataxia and peripheral neuropathy caused by XRCC1. The proposed role of $A P T X, P N K P, T D P 1$, and XRCC1 genes in repair and maintenance of single-strand break (SSB) is shown. First, the damaged base is recognized by a DNA glycosylase (not indicated). An endonuclease (APE1, for example, in A) cleaves the phosphoribose backbone, leaving a single-base gap in the DNA. A specific end-processing enzyme such as PNKP (AOA4), APTX (AOA1), or XRCC1 modifies the DNA ends to facilitate further repair. Alternatively, TDP1 (SCAN1) and TOP1 can process the ends of the DNA breaks. DNA polymerase $\beta$ removes the phosphoribose left by APE1 and fills the gap with a new base. The resulting nick is sealed by DNA ligase I or III. (B) DNA single-strand break repair (DSBR). The second group includes ataxia telangiectasia (AT, ATM), ataxia telangiectasia-like disorder (ATLD, MRE11), and recessive ataxia caused by PCNA. It is characterized by abnormal cellular responses to DNA double-strand break (DSB). The role of ATM in the cellular response to DNA damage mediated by the BRCA-associated genome complex is shown. This homologous recombination is a highly complex pathway that uses a sister chromatid as a template to repair a doublestrand DNA break. ATM is intimately associated with the MRE11-RAD50-NBS1 (MRN) complex. Following MRN complex binding, ATM is activated and autophosphorylates its inactive dimer at serine 1981. Monomeric, active ATM is then recruited to the damage site, where it phosphorylates downstream targets, including SMC1, Nbs1, Chk2, BRCA1, and histone H2AX. Furthermore, ATM phosphorylates p53 at serine 15. The DSB is recognized by the MRN complex by activation of ATM. The MRN complex and CTIP determine the DNA break point and resect the DNA to yield $3^{\prime}$ protruding ends stimulated by BRCA1. The single-stranded DNA is coated by the RPA complex. RPA is recognized by ATR, which becoming activated together with ATM promotes cell-cycle arrest. BRCA1 recruits RAD51 and initiates invasion of the DNA to the homologous region on the sister chromatid. DNA is then synthesized by DNA polymerase $\delta$ or with the assistance of PCNA by using the homologue DNA as a template. APE1, apurinic-apyrimidinic endonuclease 1; APTX, aprataxin; ATM, ataxia telangiectasia mutated; ATR, ataxia telangiectasia and RAD3-related; BRCA1, breast cancer 1; CTIP, Cterminal binding protein interacting protein; MRE11, meiotic recombination 11; NBS1, Nijmegen breakage syndrome protein 1 or Nibrin; PCNA, proliferating cell nuclear antigen; PNKP, polynucleotide kinase 3'-phosphatase; RAD50, DNA-repair protein 50; RPA complex, Replication protein A complex; TDP1, tyrosyl-DNA phosphodiesterase 1; TOP1, DNA topoisomerase 1; XRCC1, X-ray repair cross-complementing protein 1. [Color figure can be viewed at wileyonlinelibrary.com]

located in the helicase domain were more frequently associated with dystonia. ${ }^{23}$

Heterozygous mutations of SETX have been reported in patients affected with juvenile-onset amyotrophic lateral sclerosis (ALS4), ${ }^{33}$ although this is a subject of debate. $^{34}$

\section{AOA4, PNKP Gene (OMIM: 616267)}

AOA4 has been described as a combination of CA, OMA, and/or OCD, and sensorimotor peripheral neuropathy with onset between ages 1 and 9 years because of mutations in the PNKP gene. ${ }^{7}$ Some patients 
experience cognitive impairment, and brain imaging reveals cerebellar atrophy ${ }^{7,35,36}$ (Tables 2 and 3). In AOA4, AFP may be increased from 1.5 to 4 times the normal level. Some cases express low albumin levels and elevated cholesterol as in AOA1. ${ }^{36,37}$

Recently, a patient with very late onset (50 years) AOA4 had been described who had ataxia, polyneuropathy, OMA, and cognitive impairment. ${ }^{38}$

AOA4 may be the second most frequent recessive ataxia in Portugal, after Friedreich's ataxia. ${ }^{7}$ Elsewhere, PNKP mutations underlie another neurodevelopmental disorder named microcephaly with seizures. ${ }^{39}$ The PNKP gene encodes PNKP that has a crucial role in DNA damage repair ${ }^{40}$ (Fig. 3), including both singlestrand breaks (SSBs) (Fig. 2A) and double-strand breaks. $^{41}$

\section{Elevated AFP in ARCAs (AT, AOA1, AOA2, AOA4, and ARCA3)}

AFP is a $70-\mathrm{kDa}$ glycoprotein produced by the liver that is involved in the transport of different ligands, chemotaxis, oxygen free radical scavenging, and lipid peroxidation. ${ }^{42,43}$ During physiological development, an inverse correlation exists between serum concentrations of AFP and albumin. ${ }^{44}$

Among ARCAs, elevated AFP is typical of patients with $\mathrm{AT}$ or $\mathrm{AOA} 2^{42}$ and may be encountered in AOA4, AOA1, and to some extent ARCA3. ${ }^{7,25,28,45}$ ARCA3, which is due to mutations of ANO10, a calcium-activated chloride channel, ${ }^{46}$ causes progressive CA with cerebellar atrophy, optional extensor plantar reflexes, and spasticity, although without peripheral neuropathy, OCD, OMA, or movement disorders. Almost all patients with AOA2 and AT have increased AFP serum levels over the course of the disease, higher in fact than in patients with AOA1, whose AFP levels remain above controls. ${ }^{25}$ Mariani et al. ${ }^{28}$ have reported that application of discriminatory thresholds of AFP could be helpful in distinguishing AOA1, AOA2, and AT with high specificity and predictive values. The levels include: AT: AFP $>65 \mu \mathrm{g} / \mathrm{L}$; AOA2: $15 \mu \mathrm{g} /$ $\mathrm{L}<\mathrm{AFP}<65 \mu \mathrm{g} / \mathrm{L} ;$ AOA4: $10 \mu \mathrm{g} / \mathrm{L}<\mathrm{AFP}<30 \mu \mathrm{g} / \mathrm{L}$; AOA1 and ARCA3: $5 \mu \mathrm{g}<\mathrm{AFP}<20 \mu \mathrm{g} / \mathrm{L}$ (Table 2). The same study reported that AFP levels of 7 to $15 \mu \mathrm{g} / \mathrm{L}$ had a specificity of $93 \%$, positive predictive value (PPV) of $78 \%$, and negative predictive value (NPV) of $86 \%$ for patients with AOA1 relative to AOA2 and AT; AFP levels of 15 to $65 \mu \mathrm{g} / \mathrm{L}$ had a specificity of $86 \%$, PPV of $64 \%$, and NPV of $89 \%$ for patients with AOA2 relative to AOA1 and AT; AFP levels greater than $65 \mu \mathrm{g} / \mathrm{L}$ had a specificity of $90 \%$, PPV of $83 \%$, and NPV of $73 \%$ for patients with AT relative to AOA1 and AOA2. ${ }^{28}$

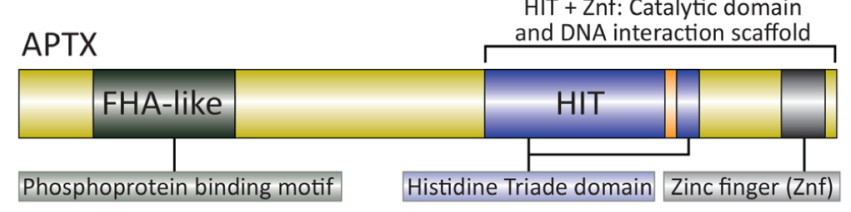

SETX
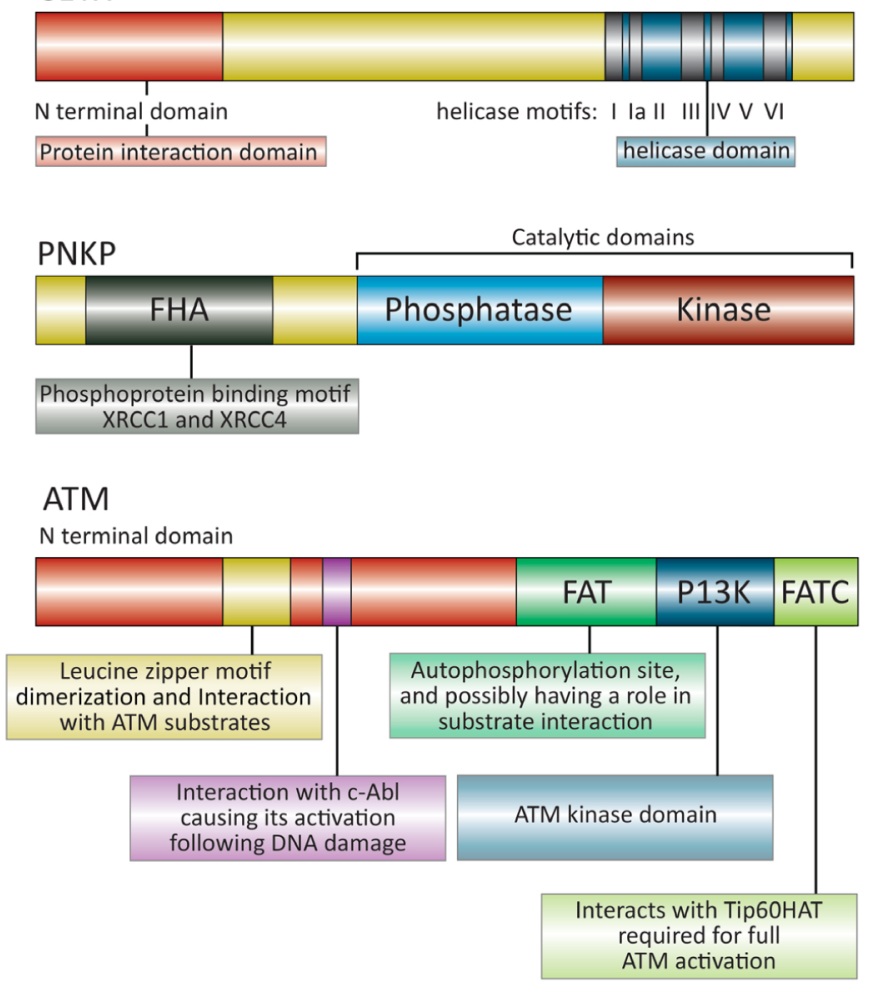

FIG. 3. Schematic representation of the domains of the APTX, SETX, PNKP, and ATM proteins (AOA1, AOA2, AOA4, and AT). APTX and PNKP: APTX interacts with several proteins involved in excision repair. FHA represents the forkhead-associated domains in APTX and PNKP, while HIT and Zinc finger represent the histidine triad and Zinc finger domains in APTX. The HIT motif $(\mathrm{HxHxH})$ is highlighted in orange. For PNKP, we show only the pathogenic variants for AOA4, because interestingly, they are located on the inside of the kinase domain for AOA4, but not MCSZ. SETX: the Senataxin protein diagram shows two key domains, including the amino-terminal protein interaction domain and the helicase domain (with the seven regions of highest conservation indicated as helicase motifs). ATM: the ATM protein is a nuclear serine/ threonine protein kinase activated by autophosphorylation after DNA damage. We show the domain architecture of ATM and the associated functions. The ATM protein has a focal adhesion targeting domain, a kinase domain, and focal adhesion targeting $\mathrm{C}$-terminal domain at the extreme $\mathrm{C}$ terminus. The $\mathrm{C}$-terminal kinase domain of ATM classifies it in the PIKK superfamily of protein kinases. AFP, alpha-fetoprotein; AOA1, ataxia with oculomotor apraxia type 1; AOA2, ataxia with oculomotor apraxia type 2; AOA4, ataxia with oculomotor apraxia type 4; APTX, aprataxin; AT, ataxia telangiectasia; ATM, ataxia telangiectasia mutated; FAT, focal adhesion targeting; FATC, FAT C-terminus; FHA, Forkhead-associated domain; HIT, histidine triad; MCSZ, microcephaly with seizures; PI3K, phosphatidylinositol 3-kinase; PNKP, polynucleotide kinase 3'-phosphatase; PIKK, phosphatidylinositol 3-kinase-related kinase; SETX, senataxin; XRCC1, X-ray repair cross-complementing protein 1. [Color figure can be viewed at wileyonlinelibrary.com]

Only in very rare cases is AFP normal in AT, while serum AFP increases continuously with age in patients with classical AT disease. ${ }^{17}$ Thus, even if initially 
normal, AFP serum level assessments should be repeated during the evolution of CA, dystonia, and/or chorea of unknown etiology (Table 2).

Elevated AFP level in these ARCAs could be an epiphenomenon not directly linked to DNA repair disruption but to liver transcriptional dysregulation., ${ }^{1,47}$ Indeed, ATM kinase has many effects, not only on DNA repair, explaining the predisposition to cancers, but also on transcription, which could induce both neurological signs and hepatic effects leading to increased AFP.

In AOA1, elevated AFP and hypoalbuminemia are two consequences of transcriptional impairment in the liver, where AFP and albumin genes have transcriptional regulatory mechanisms of opposite character. ${ }^{43,44}$ We may hypothesize that the same mechanism exists in AOA4, because hypoalbuminemia has also been described in this recently identified entity. ${ }^{36}$

In ARCA3, the AFP serum level has been found to increase mildly in two cases [16.6 and $11.6 \mu \mathrm{g} / \mathrm{L}$ (normal $<5 \mu \mathrm{g} / \mathrm{L})]$ in a previous series of nine patients. ${ }^{45}$ Whether AFP could be a biomarker for ARCA3 remains to be elucidated by further analysis of future cases.

\section{DNA Repair Pathways (AT, AOA1, AOA2, and AOA4) and Susceptibility to Malignancies (AT)}

Patients with AT have a highly increased incidence of cancers (approximately 38\% lifetime risk despite the short life span), not only lymphomas and leukemias, but also lymphoid and solid tumors (breast cancer, pancreatic cancer, and melanoma). ATM is known as the central regulator of the DNA damage response (Fig. 2B). During induction of DNA double-strand breaks, the MRN complex, containing Mre11, Rad50, and $\mathrm{Nbs} 1$, binds to the damaged site. ${ }^{4,50}$ Loss of Nbs1, which is responsible for Nijmegen breakage syndrome 1 , leads to a different phenotype, characterized by microcephaly, short stature, and recurrent infections, but not AFP elevation. ${ }^{49}$ Rad50 deficiency, named Nijmegen breakage syndrome-like disorder, includes microcephaly, intellectual deficiency, short stature, and lymphoid malignancy. ${ }^{51}$ Activation and repression of ATM's downstream targets leads to senescence, genome repair, or apoptosis ${ }^{52}$ (Figs. $2 \mathrm{~B}$ and 3 ). It has not yet been elucidated whether ATLD confers a risk for malignancies, but two brothers with ATLD died of lung cancer at ages 9 and 16 years, respectively, which is unusual. ${ }^{53}$ Susceptibility to cancer has not been described for AOA1, AOA2, or AOA4.

The presence of a common single-strand break repair pathway links AOA1, AOA2, and AOA4. Tyrosyl DNA-phosphodiesterase 1 (TDP1), aprataxin (APTX), and polynucleotide kinase/phosphatase (PNKP) each act on a discrete set of modified strand-break termini ${ }^{54}$ (Fig. 2A). Spinocerebellar ataxia with axonal neuropathy (SCAN1) caused by mutated TDP1 is another ARCA due to defective SSB repair, especially arising from abortive topoisomerase-1 activity. ${ }^{55}$ Similar to AT, AOA1, and AOA4, patients with SCAN1 have ataxia with CA, although the onset of the disease is delayed, and OCD, OMA, or elevated AFP were not reported. ${ }^{56}$ However, the biological features of SCAN1 include hypoalbuminemia and hypercholesterolemia, as in AOA1.

Many DNA repair syndromes are known to be associated with transcriptional defects, and disruptions in transcription could contribute to clinical variations, as happens in subgroups of xeroderma pigmentosum (XP) and related syndromes characterized by skin damage. Recently, two patients were described with CA and chorea as a result of mutations in ERCC4 encoding XPF (XP type F) protein. ${ }^{57} \mathrm{XPF}$ is part, with ERCC1, of a two-subunit nuclease, which participates in nucleotide excision repair of DNA and in chromosome stability maintenance. Here, too, neurodegeneration may be related to transcriptional disruptions rather than to a DNA repair defect, because the dual role of XP factors in both nucleotide excision repair and initiation of transcription is well established. ${ }^{58}$ Whereas DNA repair is significantly altered among the ARCAs with elevated AFP, and because DNA repair defects account for susceptibility to malignancies, we hypothesize that transcriptional deficiency could account for the neurodegeneration in all ARCAs with elevated AFP.

\section{Clinical and Biological Overlap Between ARCAs With OMA and/or OCD and Elevated AFP}

In clinical practice, the association of early-onset progressive CA with OMA and/or OCD and AFP is very suggestive of a limited number of ARCAs: AT, AOA1, AOA2, and AOA4. OMA is an interesting oculomotor finding, but its definition remains controversial. OMA (see earlier) was initially described under congenital conditions as the inability to turn the eyes voluntarily in a direction that aligns with a compensatory head movement. $^{2,59}$ However, because apraxia is defined as the inability to move a certain part of the body in accordance with a proposed purpose, the motility of this part being otherwise preserved, ${ }^{59}$ the word "apraxia" is not really appropriate to describe oculomotor disorders in this group of ARCAs, given that the motility of the eyes is not preserved. Whereas repetitive, hypometric saccades or a saccade of increased latency may be difficult to distinguish without oculographic recording, it may be much easier to recognize head 
thrust and OCD than genuine OMA (Supporting Information Videos S1, S6, S9, and S10). In contrast with AT, genuine OMA may not be present in AOA1 (where very hypometric saccades are seen frequently) or AOA2 (Tables 2 and 3). Thus, we may consider that OCD, head thrust, and to some extent hypometric staircase saccades should be used where appropriate, rather than the misleading OMA, to describe the oculomotor abnormalities (Supporting Information Videos S1, S6, S8, S9, and S10). OMA has not often been found in other ARCAs; therefore, when present in the context of ataxia, it is very suggestive of either AOA1, AOA2, AOA4, AT, or ATLD, although its presence does not help distinguish between these entities. At present, video-oculography cannot differentiate $\mathrm{AT}, \mathrm{AOA} 1$, and AOA2, and is not mandatory in the diagnostic workup of patients suspected to have ARCA; an appropriate oculomotor examination remains crucial. ${ }^{28}$ Complex oculomotor impairment, including gaze-evoked nystagmus, hypermetric saccades, hypometric saccades, saccades with increased latencies, and antisaccade task disturbances, reflects diffuse cerebellar (including flocculus/paraflocculus, fastigial nuclei, and vermis), as well as pons, midbrain, and parietofrontal cortex, involvement in these entities. $2,24,28,60$

Age at onset and disease progression may be helpful in distinguishing ARCAs with elevated AFP. ${ }^{1,54}$ The mean age at onset in AT, AOA1, and AOA4 has been reported to be lower than in AOA2. The course of AOA2 appears to be less severe than in AT or AOA1. Patients with AOA2 become wheelchair bound following a mean disease duration of 15 to 20 years, whereas most patients with AT and AOA1 are wheelchair bound after a mean disease duration of 10 and 11 years, respectively ${ }^{24,61}$ (Tables 2 and 3). Forms of AT in adults have been described either with early onset but a slow disease progression and sustained survival, or with a later onset (such as AOA1, or even later, such as AOA2). Thus, when assessed in adulthood, the severity and picture of AT, AOA1, and AOA2 may be surprisingly similar, including complex oculomotor disturbances, movement disorders, and elevated AFP. ${ }^{30,62}$

A combination of several types of movement disorder are commonly found in AT, ATLD, AOA1, AOA2, and AOA4. Dystonia may be encountered in almost all patients with AT, AOA1, AOA2, and AOA4 ${ }^{63}$ (Supporting Information Videos S2, S5, S8, and S12). Chorea is also found in all of these entities, but more frequently in AOA $1 .^{63}$ Interestingly, chorea and/or dystonia may improve during the course of AOA1. ${ }^{24}$ Hyperkinesias were reported to improve spontaneously over time in one patient with AOA4. ${ }^{36}$ Myoclonus is more frequent in AT than in AOA1 and AOA2. Parkinsonism seems to be more specific in AT, but it is found in only a third of patients with $\mathrm{AT} .{ }^{30}$ Dopaminergic nigrostriatal neuron loss has been reported in some patients with AOA1 in the absence of obvious parkinsonism. ${ }^{64}$ Occasionally, rather than CA, the hyperkinetic movement disorder may be the initial and/or most prominent sign of the disease. It should be kept in mind that cases of isolated dystonia, myoclonus dystonia, or chorea also occur, particularly in $\mathrm{AT}^{65,66}$ (Tables 2 and $3)$. Furthermore, prominent camptocormia has been reported in $\mathrm{AT}^{67}$

In 2019, Ronsin et al. ${ }^{68}$ reported a new MRI abnormality in AOA. Hypointensity caused by iron deposition normally observed on susceptibility weighted imaging in the dentate nuclei is not observed in patients with AOA. Thus, loss of low signal in the dentate nuclei on fluidattenuated inversion recovery (FLAIR) and susceptibility weighted imaging could be a promising marker of AOA.

\section{Diagnostic Strategies for ARCAs, Therapeutic Options, and Management in Clinical Practice}

Currently, the number of genes that when mutated lead to ataxia increases every month thanks to nextgeneration sequencing (NGS). ${ }^{69}$ Our team created and validated the Recessive Ataxia Ranking Differential Diagnosis Algorithm (RADIAL), designed to improve the differential diagnostic approach toward ARCA by using patient features to predict the underlying gene responsible. ${ }^{70}$ AFP assessment may guide the reverse phenotyping in case of first genotyping (ie, laboratory tests are performed based on the results of NGS, but not prior to the technique), and it may be helpful to interpret the multiple variants of unknown significance provided by premature NGS (ie, NGS performed before suitable phenotyping).

Today, the tendency is not to perform direct sequencing except for particular cases (very high AFP and/or telangiectasia for AT), or if an additional case has been diagnosed in the same family. Targeted-panel NGS is an interesting approach, because it provides a reliable clinical application. ${ }^{71}$ Whole-exome sequencing (WES) is an alternative genetic testing approach, particularly in patients for whom targeted-panel methodologies have not identified causative sequence variations or the clinical presentation is very complex (with multiple neurological and/or extraneurological signs), especially when the DNA of the parents is available. For patients in whom genetic disease is strongly suspected and targeted-panel sequencing and WES have both failed, whole-genome sequencing should be considered. ${ }^{72}$ WES or even whole-genome sequencing will probably become the first-line genetic test in the near future. In all cases, though, we recommend proper clinical examination, brain MRI, electromyography, and some biomarkers, such as AFP and vitamin E, before genetic testing to define the phenotype as precisely as possible. 
Symptomatic, multidisciplinary management involving physiotherapy, speech therapy, management of orthopedic complications, and spasticity is necessary for each patient, as well as treatment of pain, anxiety, or depression when present. Intensive home-based speech therapy can improve dysarthria in ARCAs. ${ }^{73}$ Continuous coordinative training leads to long-term improvements that translate to real-world function. ${ }^{74}$

These measures improve the quality of life by trying to minimize the consequences of symptoms in everyday life. The establishment of a molecular diagnosis is crucial to provide suitable genetic counseling for patients and their relatives, diagnose treatable ARCAs, ${ }^{1,77}$ and include willing patients in clinical trials. Confirmation of the diagnosis of AT at an early stage can have important implications because of the risk for cancers (in patients and parents), recurrent infections, and avoidance of ionizing radiation.

Oxidative stress has been identified recurrently in different progressive cerebellar diseases and represents a widely investigated target for treatment. ${ }^{75}$ In 2015, Romano et al. $^{76}$ described a novel and potentially important application of riluzole in patients with SCA or Friedreich's ataxia. The investigators noted that riluzole significantly improved ataxia at 3 and 12 months, and supported the idea that it could be a treatment for CA. Disease-specific trials, some already in progress in ataxia, are needed to confirm whether these findings can be applied in clinical practice. An ongoing French clinical trial assesses the efficacy of CoQ10 versus placebo in AOA1 patients, because CoQ10 deficiency has been reported in some patients with AOA1.

Gene-related therapy increasing genetic expression is a promising approach, because many ARCAs are caused by mutations leading to loss of function. Generelated therapies for ARCAs have been developed furthest in Friedreich's ataxia; recent strategies to restore frataxin have revealed a potential for slowing or even stopping disease progression. Several of the treatment principles might well be applicable by analogy to other ARCAs in the future. ${ }^{77}$

Hoch et al. ${ }^{78}$ have identified PARP1 as a possible target for treating CAs associated with an unrepaired SSB. The development of selective inhibitors of PARP1 that prevent DNA binding by this enzyme could have therapeutic potential.

Future research in cerebellar dysfunction should include analysis of specific and potential candidate drugs for both symptomatic and disease-modifying studies, with sensitive clinical measures and reliable biomarkers. ${ }^{77,79}$ Novel therapies that target deleterious pathways, such as therapies acting on RNA, are also under development. ${ }^{80}$

Acknowledgments: We thank Louise Laure Mariani and Jean Marie Ravel for help in creating the figures.

\section{References}

1. Anheim M, Tranchant $\mathrm{C}$, Koenig $\mathrm{M}$. The autosomal recessive cerebellar ataxias. N Engl J Med 2012;366:636-646.

2. Panouillères $M$, Frismand $S$, Sillan $O$, Urquizar $C$, Vighetto $A$, Pélisson D, Tilikete C. Saccades and eye-head coordination in ataxia with oculomotor apraxia type 2. Cereb Lond Engl 2013;12: $557-567$.

3. Nanetti L, Cavalieri S, Pensato V, et al. SETX mutations are a frequent genetic cause of juvenile and adult onset cerebellar ataxia with neuropathy and elevated serum alpha-fetoprotein. Orphanet J Rare Dis 2013;8:123.

4. Savitsky K, Bar-Shira A, Gilad S, et al. A single ataxia telangiectasia gene with a product similar to PI-3 kinase. Science 1995;268:1749_ 1753.

5. Moreira MC, Barbot C, Tachi N, et al. The gene mutated in ataxiaocular apraxia 1 encodes the new HIT/Zn-finger protein aprataxin. Nat Genet 2001;29:189-193.

6. Moreira M-C, Klur S, Watanabe M, et al. Senataxin, the ortholog of a yeast RNA helicase, is mutant in ataxia-ocular apraxia 2. Nat Genet 2004;36:225-227.

7. Bras J, Alonso I, Barbot C, et al. Mutations in PNKP cause recessive ataxia with oculomotor apraxia type 4. Am J Hum Genet 2015;96: 474-479.

8. Chun HH, Gatti RA. Ataxia-telangiectasia, an evolving phenotype. DNA Repair 2004;3:1187-1196.

9. Rothblum-Oviatt C, Wright J, Lefton-Greif MA, SA MG-M, Crawford TO, Lederman HM. Ataxia telangiectasia: a review. Orphanet J Rare Dis 2016;11:159.

10. Micol R, Slama LB, Suarez F, et al. Morbidity and mortality from ataxia-telangiectasia are associated with ATM genotype. J Allergy Clin Immunol 2011;128:382-389.e1.

11. Cummins G, Jawad T, Taylor M, Lynch T. Myoclonic head jerks and extensor axial dystonia in the variant form of ataxia telangiectasia. Parkinsonism Relat Disord 2013;19:1173-1174.

12. Levy A, Lang AE. Ataxia-telangiectasia: a review of movement disorders, clinical features, and genotype correlations. Mov Disord Off J Mov Disord Soc 2018;33(8):1238-1247. https://doi.org/10.1002/ mds. 27319

13. Reiman A, Srinivasan V, Barone G, et al. Lymphoid tumours and breast cancer in ataxia telangiectasia; substantial protective effect of residual ATM kinase activity against childhood tumours. $\mathrm{Br} \mathrm{J}$ Cancer 2011;105:586-591.

14. Mandola AB, Mandola AB, Reid B, et al. Ataxia telangiectasia diagnosed on newborn screening-case cohort of 5 years' experience. Front Immunol 2019;10:2940.

15. Schoenaker MHD, Blom M, de Vries MC, Weemaes CM, van der Burg M, Willemsen MA. Early diagnosis of ataxia telangiectasia in the neonatal phase: a parents' perspective. Eur J Pediatr 2020;179: 251-256.

16. van Os NJH, Haaxma CA, van der Flier M, et al. Ataxia-telangiectasia: recommendations for multidisciplinary treatment. Dev Med Child Neurol 2017;59:680-689.

17. Stray-Pedersen A, Borresen-Dale AL, Paus E, Lindman CR, Burgers T, Abrahamsen TG. Alpha fetoprotein is increasing with age in ataxia-telangiectasia. Eur J Paediatr Neurol 2007;11: 375-380.

18. Liu W, Narayanan V. Ataxia with oculomotor apraxia. Semin Pediatr Neurol 2008;15:216-220.

19. Gatti RA, Berkel I, Boder E. Localization of an ataxia-telangiectasia gene to chromosome 11q22-23. Nature 1988;336:577-580.

20. Palmeri S, Rufa A, Pucci B, et al. Clinical course of two Italian siblings with ataxia-telangiectasia-like disorder. Cereb Lond Engl 2013; 12:596-599.

21. Stewart GS, Maser RS, Stankovic T, et al. The DNA double-strand break repair gene hMRE11 is mutated in individuals with an ataxiatelangiectasia-like disorder. Cell 1999;99:577-587.

22. Keijzers G, Bakula D, Scheibye-Knudsen M. Monogenic diseases of DNA repair. N Engl J Med 2017;377:1868-1876. 
23. Anheim M, Monga B, Fleury M, et al. Ataxia with oculomotor apraxia type 2: clinical, biological and genotype/phenotype correlation study of a cohort of 90 patients. Brain J Neurol 2009;132: 2688-2698.

24. Le Ber I, Moreira MC, Rivaud-Péchoux S, et al. Cerebellar ataxia with oculomotor apraxia type 1: clinical and genetic studies. Brain J Neurol 2003;126:2761-2772.

25. Renaud M, Moreira MC, Monga BB, et al. Clinical, biomarker, and molecular delineations and genotype-phenotype correlations of ataxia with oculomotor apraxia type 1. JAMA Neurol 2018;75(4): 495-502. https://doi.org/10.1001/jamaneurol.2017.4373

26. Castellotti B, Mariotti C, Rimoldi M, et al. Ataxia with oculomotor apraxia type1 (AOA1): novel and recurrent aprataxin mutations, coenzyme Q10 analyses, and clinical findings in Italian patients. Neurogenetics 2011;12:193-201.

27. Le Ber I, Dubourg O, Benoist JF, et al. Muscle coenzyme Q10 deficiencies in ataxia with oculomotor apraxia 1. Neurology 2007;68: 295-297.

28. Mariani LL, Rivaud-Péchoux S, Charles P, et al. Comparing ataxias with oculomotor apraxia: a multimodal study of AOA1, AOA2 and AT focusing on video-oculography and alpha-fetoprotein. Sci Rep 2017;7:15284

29. Becherel OJ, Fogel BL, Zeitlin SI, Samaratunga H, Greaney J, Homer H, Lavin MF. Disruption of spermatogenesis and infertility in ataxia with oculomotor apraxia type 2 (AOA2). Cereb Lond Engl 2019;18:448-456.

30. Méneret A, Ahmar-Beaugendre Y, Rieunier G, et al. The pleiotropic movement disorders phenotype of adult ataxia-telangiectasia. Neurology 2014;83:1087-1095.

31. Watanabe M, Sugai Y, Concannon P, et al. Familial spinocerebellar ataxia with cerebellar atrophy, peripheral neuropathy, and elevated level of serum creatine kinase, gamma-globulin, and alpha-fetoprotein. Ann Neurol 1998;44:265-269.

32. Suraweera A, Lim Y, Woods R, Birrell GW, Nasim T, Becherel OJ, Lavin MF. Functional role for senataxin, defective in ataxia oculomotor apraxia type 2, in transcriptional regulation. Hum Mol Genet 2009; 18:3384-3396

33. Hirano $M$, Quinzii CM, Mitsumoto $H$, Hays AP, Roberts JK, Richard P, Rowland LP. Senataxin mutations and amyotrophic lateral sclerosis. Amyotroph Lateral Scler Off Publ World Fed Neurol Res Group Mot Neuron Dis 2011;12:223-227.

34. Arning L, Epplen JT, Rahikkala E, Hendrich C, Ludolph AC, Sperfeld AD. The SETX missense variation spectrum as evaluated in patients with ALS4-like motor neuron diseases. Neurogenetics 2013; 14:53-61.

35. Tzoulis C, Sztromwasser P, Johansson S, Gjerde IO, Knappskog P, Bindoff LA. PNKP mutations identified by whole-exome sequencing in a norwegian patient with sporadic ataxia and edema. Cerebellum Lond Engl 2017;16:272-275.

36. Paucar M, Malmgren H, Taylor M, Reynolds JJ, Svenningsson P, Press R, Nordgren A. Expanding the ataxia with oculomotor apraxia type 4 phenotype. Neurol Genet 2016;2:e49.

37. Schiess N, Zee DS, Siddiqui KA, Szolics M, El-Hattab AW. Novel PNKP mutation in siblings with ataxia-oculomotor apraxia type 4. J Neurogenet 2017;31:23-25.

38. Campopiano R, Ferese R, Buttari F, et al. A novel homozygous variant in the fork-head-associated domain of polynucleotide kinase phosphatase in a patient affected by late-onset ataxia with oculomotor apraxia type 4. Front Neurol 2019;10:1331.

39. Shen J, Gilmore EC, Marshall CA, et al. Mutations in PNKP cause microcephaly, seizures and defects in DNA repair. Nat Genet 2010; $42: 245-249$

40. Jilani A, Ramotar D, Slack C, Ong C, Yang XM, Scherer SW, Lasko DD. Molecular cloning of the human gene, PNKP, encoding a polynucleotide kinase 3 '-phosphatase and evidence for its role in repair of DNA strand breaks caused by oxidative damage. J Biol Chem 1999;274:24176-24186.

41. Tahbaz N, Subedi S, Weinfeld M. Role of polynucleotide kinase/phosphatase in mitochondrial DNA repair. Nucleic Acids Res 2012;40:3484-3495.
42. Schieving $\mathrm{JH}$, De Vries $\mathrm{M}$, et al. Alpha-fetoprotein, a fascinating protein and biomarker in neurology. Eur J Paediatr Neurol 2014;18: 243-248.

43. Zubkova E, Semenkova L, Dudich E, et al. Alpha-fetoprotein contributes to THP-1 cell invasion and chemotaxis via protein kinase and Gi-protein-dependent pathways. Mol Cell Biochem 2013;379: 283-293.

44. Nayak NC, Mital I. The dynamics of alpha-fetoprotein and albumin synthesis in human and rat liver during normal ontogeny. Am J Pathol 1977;86:359-374.

45. Renaud M, Anheim M, Kamsteeg EJ, et al. Autosomal recessive cerebellar ataxia type 3 due to ANO10 mutations: delineation and genotype-phenotype correlation study. JAMA Neurol 2014;71: 1305.

46. Hartzell HC, Yu K, Xiao Q, et al. Anoctamin/TMEM16 family members are $\mathrm{Ca} 2+-$ activated cl- channels. J Physiol 2009;587: $2127-2139$.

47. Lainé J-P, Egly J-M. When transcription and repair meet: a complex system. Trends Genet TIG 2006;22:430-436.

48. Shimazaki H, Takiyama Y, Sakoe K, et al. Early-onset ataxia with ocular motor apraxia and hypoalbuminemia: the aprataxin gene mutations. Neurology 2002;59:590-595.

49. Varon R, Vissinga C, Platzer M, et al. Nibrin, a novel DNA doublestrand break repair protein, is mutated in Nijmegen breakage syndrome. Cell 1998;93:467-476.

50. Lavin MF, Kozlov S, Gatei M, Kijas AW. ATM-dependent phosphorylation of all three members of the MRN complex: from sensor to adaptor. Biomolecules 2015;5:2877-2902.

51. Waltes R, Kalb R, Gatei M, et al. Human RAD50 deficiency in a Nijmegen breakage syndrome-like disorder. Am J Hum Genet 2009; 84:605-616.

52. Shiloh Y. ATM and related protein kinases: safeguarding genome integrity. Nat Rev Cancer 2003;3:155-168.

53. Uchisaka N, Takahashi N, Sato M, et al. Two brothers with ataxiatelangiectasia-like disorder with lung adenocarcinoma. J Pediatr 2009; $155: 435-438$.

54. Jiang B, Glover JNM, Weinfeld M. Neurological disorders associated with DNA strand-break processing enzymes. Mech Ageing Dev 2017;161:130-140.

55. El-Khamisy SF, Saifi GM, Weinfeld M, et al. Defective DNA singlestrand break repair in spinocerebellar ataxia with axonal neuropathy-1. Nature 2005;434:108-113.

56. Takashima H, Boerkoel CF, John J, et al. Mutation of TDP1, encoding a topoisomerase I-dependent DNA damage repair enzyme, in spinocerebellar ataxia with axonal neuropathy. Nat Genet 2002; $32: 267-272$.

57. Compe E, Malerba M, Soler L, et al. Neurological defects in trichothiodystrophy reveal a coactivator function of TFIIH. Nat Neurosci 2007;10:1414-1422.

58. Carré G, Marelli C, Anheim M, et al. Xeroderma pigmentosum complementation group F: a rare cause of cerebellar ataxia with chorea. J Neurol Sci 2017;376:198-201.

59. Cogan DG. A type of congenital ocular motor apraxia presenting jerky head movements. Am J Ophthalmol 1953;36:433-441.

60. Pierrot-Deseilligny C, Müri RM, Ploner CJ, Gaymard B, Demeret S, Rivaud-Pechoux S. Decisional role of the dorsolateral prefrontal cortex in ocular motor behaviour. Brain J Neurol 2003;126:14601473.

61. Woods CG, Taylor AM. Ataxia telangiectasia in the British Isles: the clinical and laboratory features of 70 affected individuals. Q J Med 1992;82:169-179.

62. Verhagen MMM, Abdo WF, Willemsen MA, et al. Clinical spectrum of ataxia-telangiectasia in adulthood. Neurology 2009;73: 430-437.

63. Pearson TS. More than ataxia: hyperkinetic movement disorders in childhood autosomal recessive ataxia syndromes. Tremor Hyperkinet Mov N Y N 2016;6:368.

64. Salvatore E, Varrone A, Criscuolo C, et al. Nigrostriatal involvement in ataxia with oculomotor apraxia type 1 . J Neurol 2008;255:45-48. 
65. Charlesworth G, Mohire MD, Schneider SA, et al. Ataxia telangiectasia presenting as dopa-responsive cervical dystonia. Neurology 2013;81:1148-1151.

66. Meissner WG, Fernet M, Couturier J, et al. Isolated generalized dystonia in biallelic missense mutations of the ATM gene. Mov Disord Off J Mov Disord Soc 2013;28:1897-1899.

67. Paucar M, Schechtmann G, Taylor AM, et al. Variant ataxiatelangiectasia with prominent camptocormia. Parkinsonism Relat Disord 2019;62:253-255.

68. Ronsin S, Fernet M, Couturier J, et al. A new MRI marker of ataxia with oculomotor apraxia. Eur J Radiol 2019;110:187-192.

69. Rossi M, Anheim M, Durr A, et al. The genetic nomenclature of recessive cerebellar ataxias. Mov Disord Off J Mov Disord Soc 2018;33(7):1056-1076. https://doi.org/10.1002/mds.27415

70. Renaud M, Tranchant C, Martin JV, et al. A recessive ataxia diagnosis algorithm for the next generation sequencing era. Ann Neurol 2017;82(6):892-899. https://doi.org/10.1002/ana.25084.

71. Montaut S, Tranchant C, Drouot N, et al. Assessment of a targeted gene panel for identification of genes associated with movement disorders. JAMA Neurol 2018;75(10):1234-1245. https://doi.org/10. 1001/jamaneurol.2018.1478

72. Klein CJ, Foroud TM. Neurology individualized medicine: when to use next-generation sequencing panels. Mayo Clin Proc 2017;92:292-305.

73. Vogel AP, Stoll LH, Oettinger A, et al. Speech treatment improves dysarthria in multisystemic ataxia: a rater-blinded, controlled pilotstudy in ARSACS. J Neurol 2019;266:1260-1266.

74. Ilg W, Brötz D, Burkard S, Giese MA, et al. Long-term effects of coordinative training in degenerative cerebellar disease. Mov Disord Off J Mov Disord Soc 2010;25:2239-2246.
75. Jinnah HA, Albanese A, Bhatia KP, et al. Treatable inherited rare movement disorders. Mov Disord Off J Mov Disord Soc 2018;33: 21-35.

76. Romano S, Coarelli G, Marcotulli C, et al. Riluzole in patients with hereditary cerebellar ataxia: a randomised, double-blind, placebocontrolled trial. Lancet Neurol 2015;14:985-991.

77. Synofzik M, Puccio H, Mochel F, Schöls L. Autosomal recessive cerebellar ataxias: paving the way toward targeted molecular therapies. Neuron 2019;101:560-583.

78. Hoch NC, Hanzlikova H, Rulten SL, et al. XRCC1 mutation is associated with PARP1 hyperactivation and cerebellar ataxia. Nature 2017;541:87-91.

79. Zesiewicz TA, Wilmot G, Kuo SH, et al. Comprehensive systematic review summary: treatment of cerebellar motor dysfunction and ataxia: report of the guideline development, dissemination, and implementation Subcommittee of the American Academy of Neurology. Neurology 2018;90:464-471.

80. Manto M, Gandini J, Feil K, Strupp M. Cerebellar ataxias: an update. Curr Opin Neurol 2020;33:150-160. 